\title{
RETRACTED ARTICLE: Acute necrotizing myelitis and acute motor axonal neuropathy in a COVID-19 patient
}

\author{
Catalina Maideniuc ${ }^{1} \cdot$ Anza B. Memon ${ }^{2,3}$ \\ Received: 6 July 2020 / Revised: 2 August 2020 / Accepted: 5 August 2020 / Published online: 9 August 2020 \\ (c) Springer-Verlag GmbH Germany, part of Springer Nature 2020
}

The Editors-in-Chief have retracted this article because the same case has been previously reported by different authors [1]. This article is therefore redundant. None of the authors agree to this retraction. The online version of this article contains the full text of the retracted article as electronic supplementary material.
[1] Valiuddin, H., Skwirsk, B., \& Paz-Arabo, P. (2020). Acute Transverse Myelitis Associated with SARS-CoV-2: A Case-Report. Brain, Behavior, \& Immunity-Health.

Electronic supplementary material The online version of this article (https://doi.org/10.1007/s00415-020-10145-6) contains supplementary material, which is available to authorized users.

Anza B. Memon amemon2@hfhs.org

1 Department of Neurology, Saint Joseph Mercy Hospital, Ann Arbor, MI, USA

2 Department of Neurology, Henry Ford Hospital, 2799 W Grand Blvd, Detroit, MI 48202, USA

3 School of Medicine, Wayne State University, Detroit, MI, USA 